\title{
Evaluating Progressive Overload Changes of the Musculoskeletal System in Automobile Industry Workers
}

\author{
Anna Błaszczyk*, Magdalena Zygmańska-Jabłońska, Katarzyna Wegner-Czerniak, \\ Malgorzata B. Ogurkowska
}

Poznan University of Physical Education, Department of Biomechanics, Poznań, Poland

Received: 8 March 2019

Accepted: 21 August 2019

\begin{abstract}
The formation of overload changes is a well-known concept. Numerous factors contributing to the development of progressive overload changes have also been described, including stress, performing repetitive movements, non-physiological working position, etc. [2-4]. Production line workers constitute an occupational group that is exposed to many of the above-mentioned risk factors. Therefore, the aim of our study is to establish the most common types of musculoskeletal overloads and to investigate the effect of upper extremity overload changes in the lumbosacral spine. A survey was conducted on 111 foundry and assembly workers. Information on the location, type and intensity (VAS scale) of pain was collected. The men also defined their job seniority, type of work, number of repetitive movements performed and knowledge of work ergonomics. Pain of the highest intensity was experienced by the workers in the lumbar and cervical spine and the shoulder joints. Results of the study also show that there is a correlation between lumbar and cervical pain on the one hand, and pain in subsequent joints of the upper extremity on the other. Repeated pain episodes may also reflect the progressive nature of the overload changes.
\end{abstract}

Keywords: musculoskeletal pain; occupational disease, lower back syndrome, industry workers, automotive industry

\section{Introduction}

The notion of overload of the musculoskeletal system has been known for many years. Although musculoskeletal disorders constitute the most frequent

*e-mail: annasz1@onet.pl

conditions in Europe, prophylactic and in-depth diagnostic measures in terms of the occurrence of the overload disease are implemented infrequently [1]. The reason for the occurrence of overload changes should therefore be considered. Activities that are conducive to the development of musculoskeletal overload are defined as risk factors. These include the following: repetitive movements, improper body posture, use of heavy equipment or carrying objects whose shape and dimensions make them difficult to handle. Stress, 
obesity and quantitative requirements are also of significance [2-4]. All physical and psychophysical factors as well as the work environment affect worker health and mood. Fatigue, constant stress, anxiety and extremity and back pain are enumerated among the most frequent symptoms [5]. The nature of the work performed by male production line workers involves carrying vehicle components and performing repetitive movement patterns under significant time and efficiency pressure, which results in lumbar spine and upper extremity overload.

The automotive industry is a thriving sector of the economy [6]. In spite of the progressing robotization of production lines, car factories still employ many physical workers. It should be borne in mind that the automotive industry requires production lines to be rearranged each time before the production of a new vehicle model starts. Modernisation allows for improving workstations, including in terms of production efficiency, work safety and ergonomics. Nowadays construction teams are no longer composed solely of engineers. Physicians, physiotherapists and specialists in ergonomics are involved in constructing workstations and oversee worker safety and good health [7]. Taking the risk factors into account and performing an in-depth evaluation of every workstation are necessary in each modern enterprise. The elimination of harmful factors prevents the occurrence of musculoskeletal disorders and positively affects worker health [8]

Preventing musculoskeletal disorders also has a positive influence on the economic situation of a particular company. The healthier a worker is, the fewer health benefits $\mathrm{s} / \mathrm{he}$ uses and the more efficiently $\mathrm{s} / \mathrm{he}$ works. Irrespective of the level of economic development, there has been an increase in the number of years people work. This predisposes to musculoskeletal overload due to longer work at an older age, in both men and women. According to UN reports, in the last 6 years (2009-2015), the number of people over the age of 65 who were still employed has increased by $10 \%$ [9].

Physical work in the automotive industry requires workers to perform a lot of repetitive movements, carry heavy objects or maintain an improper body posture for extended periods of time. This makes such workers susceptible to overload changes in the musculoskeletal system. In spite of constant technological development, musculoskeletal overload still constitutes a significant problem. Athletes, health care employees (nurses and physiotherapists), musicians and cooks are the professional groups that have been studied most extensively in this respect [10-12]. Few studies have concerned production line workers and it is they who deal with biggest loads which affect their musculoskeletal system, and the very nature of their work in large industrial plants requires them to perform repetitive and often non-physiological movements. The aim of our study is to define the most frequently occurring musculoskeletal overloads and analyse the impact of upper extremity overload on overload changes of the lumbar spine in men working in the automotive industry.

\section{Experimental Procedures}

The study was carried out on 111 workers from the automotive industry. Men who were most likely to develop overload changes of the musculoskeletal system were selected for the study on the basis of a biomechanical analysis of video materials showing the workers performing their everyday activities at their workstations. Body posture, repetitiveness and type of movements as well as the necessity to carry heavy items was evaluated. Attention was also paid to the construction of the workstations and the devices and tools operated. The above criteria allowed us to select a study group composed of male assembly and foundry workers aged between 20 and 65 . The average age of the subjects was 40 years and their job seniority (as far as the automotive industry is concerned) was 8 years (Table 1).

All employees performed numerous rotational movements of the torso, often with additional loads held in their hands. Precise, repetitive movements of the upper extremities were also seen. These are usually related to the operation of a compressor or a small broom for cleaning moulds or a small hammer for finishing them. Moreover, many men lifted heavy and unwieldy components from the floor onto tables and shelves, performing the entire movement sequence in a non-ergonomic way, overloading their musculoskeletal system. The layout of many workstations was unfavourable, i.e., tools located too high, the presence of steps, and overly large and poorly designed trolleys for transporting manufactured elements.

The selected workers answered a number of survey questions concerning the occurrence of pain.

Table 1. Characteristics of research material.

\begin{tabular}{|c|c|c|c|c|c|c|}
\hline $\mathrm{n}=111$ & $\begin{array}{c}\text { Age } \\
(\text { years })\end{array}$ & $\begin{array}{c}\text { Body height } \\
(\mathrm{cm})\end{array}$ & $\begin{array}{c}\text { Body mass } \\
(\mathrm{kg})\end{array}$ & BMI & $\begin{array}{c}\text { Job seniority (total) } \\
\text { (years) }\end{array}$ & $\begin{array}{c}\text { Job seniority (current position) } \\
\text { (years) }\end{array}$ \\
\hline Average & 39,6 & 178,3 & 85,8 & 27,0 & 18,4 & 8,4 \\
\hline Minimum & 20,0 & 160,0 & 56,0 & 18,2 & $<1$ & $<1$ \\
\hline Maximum & 65,0 & 198,0 & 124,0 & 41,4 & 49,0 & 20,0 \\
\hline
\end{tabular}


The authors of this work developed a comprehensive survey exclusively for the purpose of questioning the studied group of men. Information on the location, type and intensity (VAS scale) of pain was collected. The subjects precisely described the pain they experienced and classified it in terms of type and frequency. The men also defined their job seniority, type of work and number of repetitive movements performed and the extent to which they were familiar with the rules of work ergonomics. The workers described the physical activity they engaged in both at work and in their free time. They also provided information concerning any injuries they sustained and rehabilitation they underwent. The entire research was conducted by the authors personally in the subjects' place of work. This enabled us to hold additional conversations with the workers and actually see their workstations, which were previously analysed on the basis of photographic and video materials.

\section{Results and Discussion}

The most important information acquired in the course of the study was the location and intensity of the pain most frequently experienced by workers from the automotive industry.

Lumbar pain was the most frequently reported, by $73 \%$ of the subjects. Moreover, more than $1 / 3$ of the subjects experienced lumbar pain several times a week or even daily. The patients also complained of cervical spine pain (37\%) and shoulder joint pain (33\%). Single individuals suffered from hip joint pain and foot pain.

Using the VAS scale, the patients defined their current pain intensity as well as the pain intensity during a pain episode. Analysis of the values of pain intensity during pain episodes suggests that lumbar pain is the most intense. Moreover, the employees found cervical and lumbar pain most troublesome, both during pain episodes and the time of filling in the questionnaire. Numerous instances of pain in the cervical spine prompted the author to look for a relationship between neck pain and age. The men were divided into 3 age groups: 20-34 y.o., 35-49 y.o. and 50+ y.o. In terms of the differences in the pain experienced, there was a tendency toward significance for lumbar pain intensity to increase together with age up to the age of 50 $(\mathrm{p}=0,09)$. The strongest pain (6 VAS on average) was experienced by men aged 34-49. A slight decrease in the intensity of pain, down to an average value of 5.5 points on the VAS scale, was observed among men over the age of 50 .

The patients also specified the frequency of pain. The following ranges were defined: several times a year, a month, a week or daily. With the use of the ANOVA analysis of variance, it was established that there is no relationship between the frequency and intensity of pain (VAS scale) in the lumbar spine $(p=0.39)$. However, attention should be paid to the fact that the strength of pain defined in points on the VAS scale increases together with the increase in the frequency of pain. The strongest pain -6.5 points on

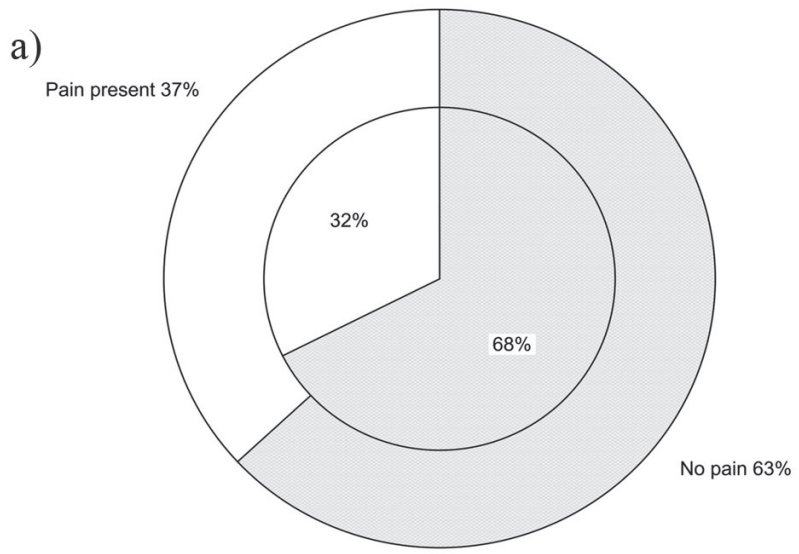

Outer circle - pain present in the cervical spine Inner circle - pain present in the shoulder

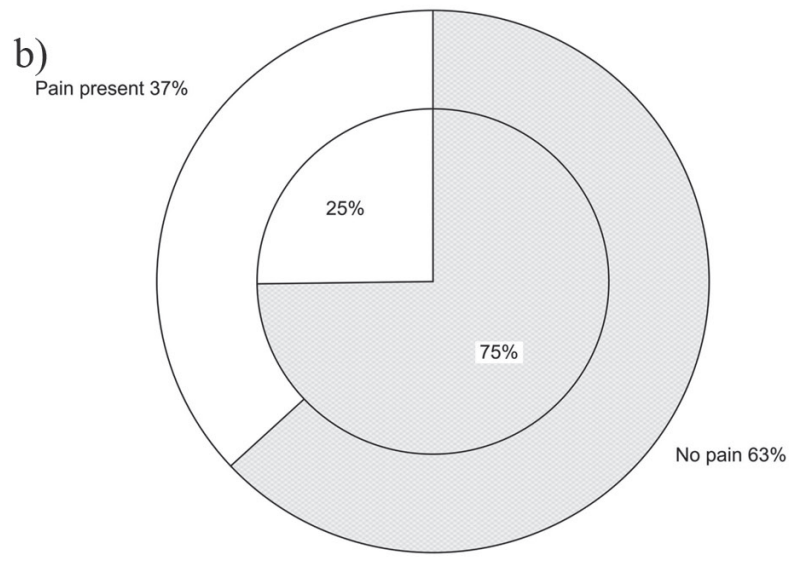

Outer circle - pain present in the cervical spine Inner circle - pain present in the elbow

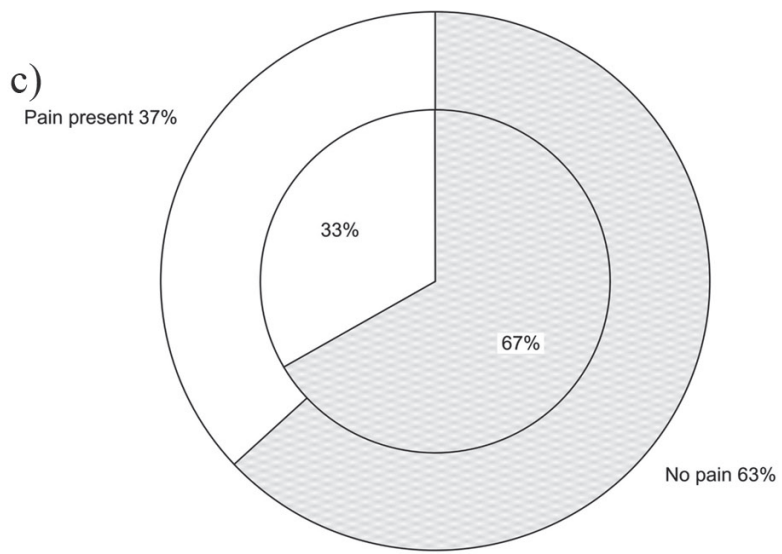

Outer circle - pain present in the cervical spine Inner circle - pain present in the wrist

Fig. 1. Percentage distribution of co-occurrence of cervical spine pain and pain in the subsequent joints of the upper extremity: a) presence of pain in the shoulders and cervical spine, b) presence of pain in the elbow joints and cervical spine, c) presence of pain in the wrist and cervical spine. 
average - was experienced by workers who experienced pain on a daily basis.

Considering the mechanism of developing overload changes, an attempt was made to establish relationships between the occurrence of pain in particular parts of the spine. It is known that changes in spine curvature (e.g., reduction of lumbar lordosis) have a negative impact on thoracic kyphosis and cervical lordosis [13]. Unfortunately, the performed analysis did not demonstrate any significant relationships between the occurrence of pain in the lumbar and cervical spine. The development of pathological overload changes in the cervical spine is related to upper extremity joint pain. Shoulder joint pain was reported by $33 \%$ of the studied men. The same percentage reported wrist pain, while elbow pain was reported by $1 / 4$ of the respondents. The chi-square test was used to determine whether there is a relationship between pain in the cervical spine and subsequent joints of upper extremities (Fig. 1a-c). There is a statistically significant difference $(\mathrm{p}=0.03)$ between individuals who experience pain in the cervical spine and wrist and the group of men who did not report such pain.

The application of the VAS scale allowed us to search for correlations between the intensity of pain in the spine and the joints of upper extremities. Given the mechanism of transferring load, it was expected that reporting spine pain would be related to the intensity of upper extremity joint pain. Analysis of pain intensity (VAS scale) of the cervical and lumbar spine and the value expressed in points of the experienced pain in the shoulder, elbow and wrist yielded very interesting results (Fig. 2a-h). It turns out that there is a statistically significant correlation between the pain in shoulder joints and cervical spine pain. An increase in the intensity of pain in the cervical spine entails an increase in the intensity of pain in the shoulder joints reported by workers of the automotive industry. Moreover, there is also a correlation between the intensity of pain in the elbow and wrist joints on the one hand and cervical spine pain on the other hand. The stronger the cervical spine pain reported by workers, the higher the estimated values of pain in the elbow joints and, analogically wrist joints. It was also observed that an increase in the intensity of shoulder pain was accompanied by an increase in the intensity of pain in the elbow joints. There is a similar statistically significant correlation in the case of lumbar and cervical spine. This may be indicative of the progressive nature of overload changes of the musculoskeletal system. All the presented Spearman's rank correlations are statistically significant (except Fig. 2c) and were calculated using Statistica software. From an engineering point of view, Spearman's rank correlations referred to in this paper are more focused on concordance of the ranking, while Pearson's correlations are focused on values. In further studies, a copula model should be used, as it can describe different types of dependencies that include association concepts such as concordance, linear correlation and other related measures [14-16]. Copula is therefore much more flexible than traditional concepts (Kendall, Spearman or Pearson) to characterize dependencies and includes these concepts. Copula models provide a very flexible way to model multivariate dependencies. Given its high usability, it has already been used in many different applications within the scope of engineering, reliability engineering [17], and economics [18].

Pain intensity in the subsequent upper extremity joints (VAS scale) was also correlated with the number of repetitive movements performed during one working day. Calculations performed for the shoulder joint, elbow joint and wrist joint did not bear any relationship to the number of repetitive movements performed. It should be taken into account that both parameters referred to above (intensity of pain and number of movements) were estimated by the men. They found it problematic to define the actual number of repetitive movement patterns performed during one working day. The large variability of results may suggest that workers on a particular position were unable to precisely define the number of repetitive activities they performed. The repetitive nature of the work, based on established movement patterns, was clearly visible on the video materials which were analysed during the first stage of the study.

Studies show that lumbar pain affects $85 \%$ of adult society [1]. In European countries such as Greece, Slovenia and Poland, as many as $49 \%$ of professionally active people report back pain [19]. Research confirms these statistics and shows that lumbar pain is the most frequently reported ailment among physical workers. There are many reasons for the constant increase in the percentage of people complaining of spine pain. These include insufficient physical activity, poor education, lack of knowledge on work ergonomics and bad habits [20]. The average intensity of lower back pain during pain episodes in physical workers was $5.8 \pm 2.2$ on the VAS scale. For comparison, researchers from California were studying a similar group and their average pain intensity was $4.2 \pm 1.3$ points on the VAS scale [21]. Last year Kruger performed an analogous study on full-time workers with an average pain intensity of $5.4 \pm 1.8$ [22]. In all the publications referred to above, research groups comprised individuals who experienced pain in the lumbar spine for at least three months. According to such reports, the average value of lumbar pain intensity among physical workers from the automotive industry seems to be high. Moreover, reporting repeated pain episodes may be indicative of chronic overload changes.

Given the mechanism of compensation which consists in transferring load, the co-occurrence of lumbar and cervical pain was analysed. Dysfunctions of the lower back undoubtedly have an impact on changes in the curvature of the cervical spine [13]. It has been proven that rehabilitation of the cervical spine has a positive impact on the biomechanics of the lumbar spine [23]. Both cervical and lumbar pain were reported 
a)

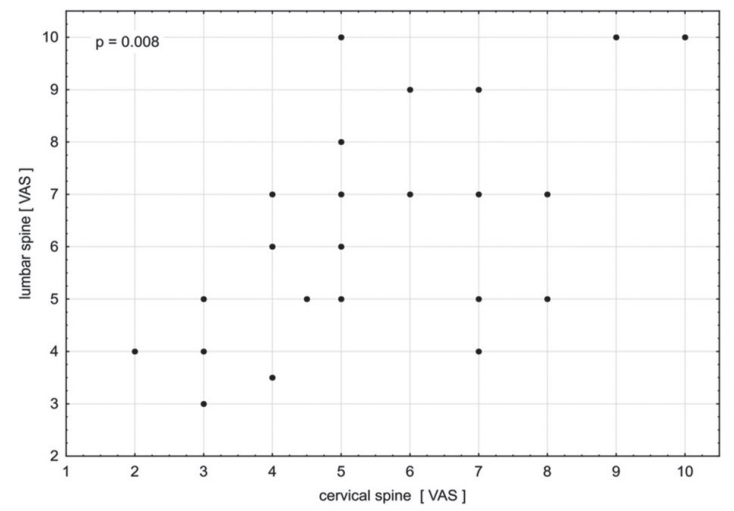

c)

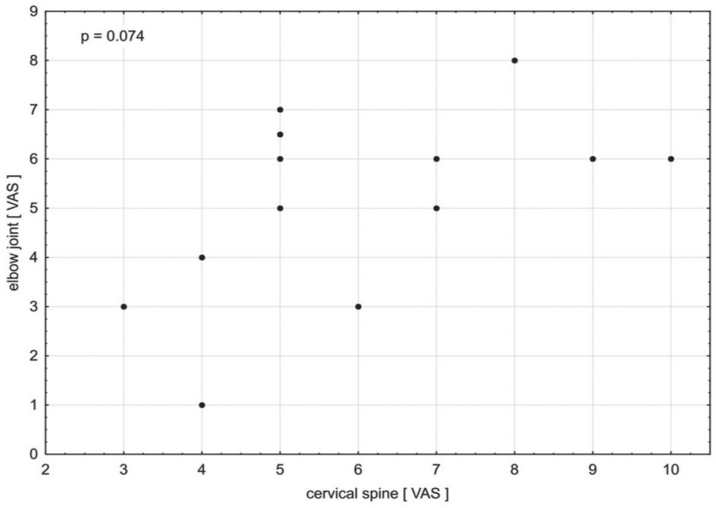

e)

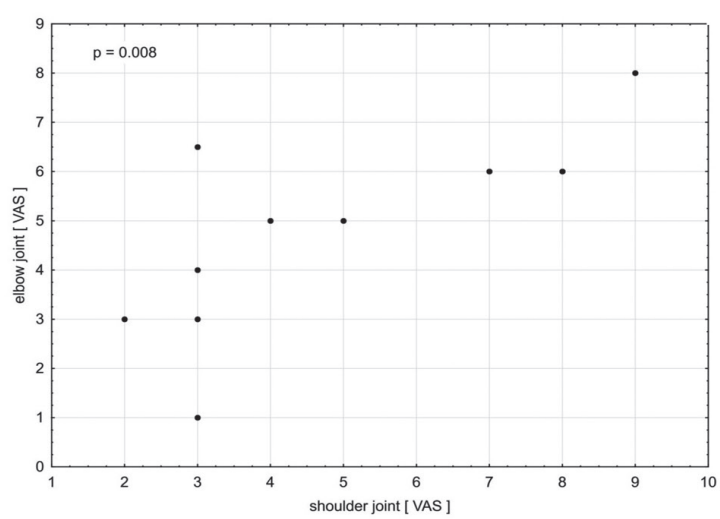

g)

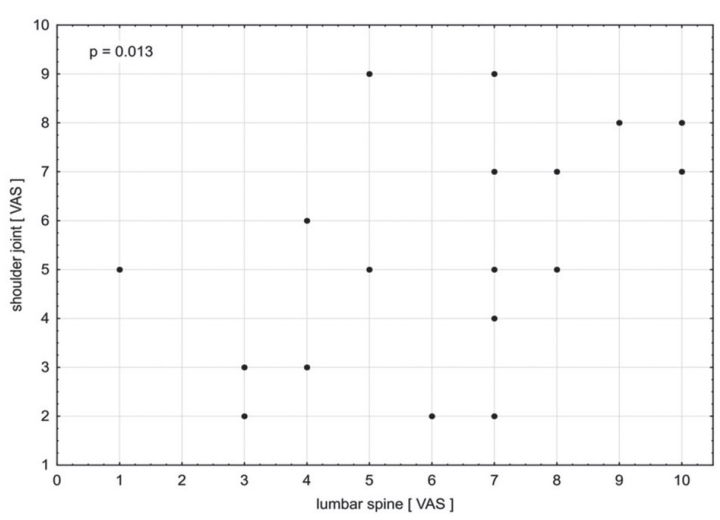

b)

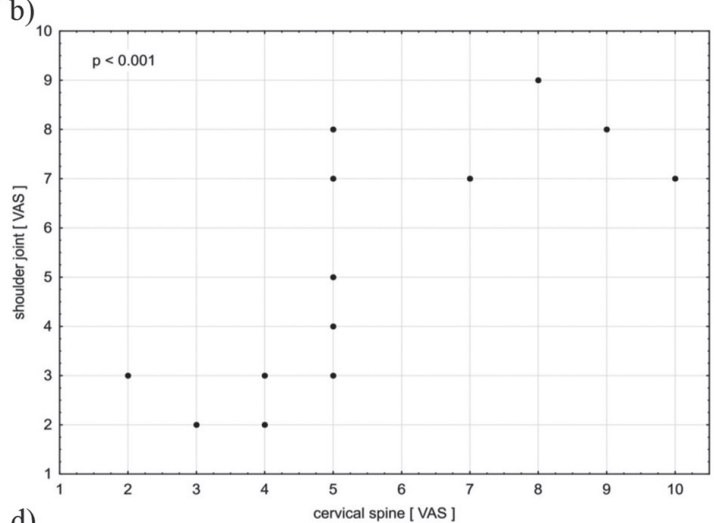

d)
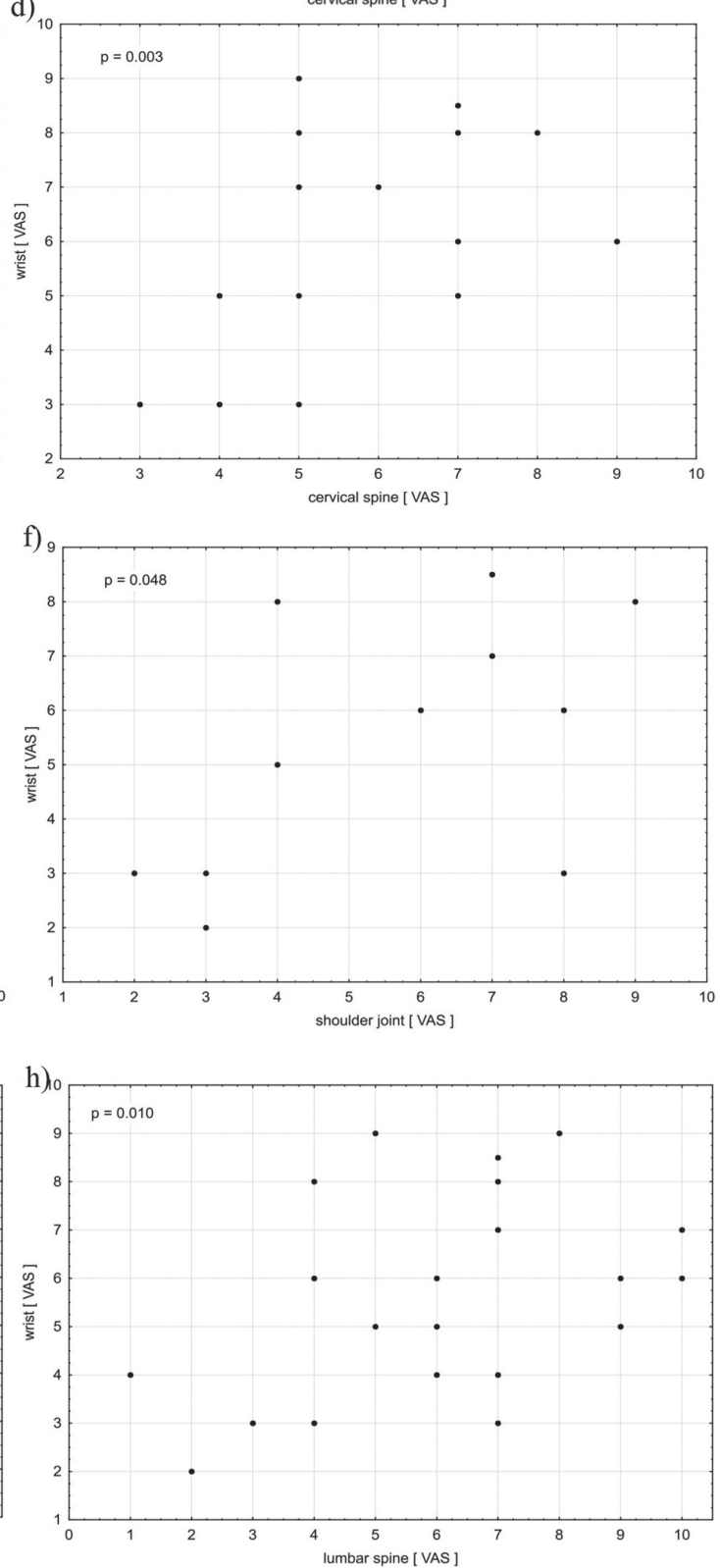

Fig. 2. Scatter diagrams: a) correlation between the intensity of lumbar spine pain in relation to the intensity of cervical spine pain, b) correlation between the intensity of shoulder joint pain in relation to the intensity of cervical spine pain, c) correlation between the intensity of elbow joint pain in relation to the intensity of cervical spine pain, d) correlation between the intensity of wrist pain in relation to the intensity of cervical spine pain, e) correlation between the intensity of elbow joint pain in relation to the intensity of shoulder joint pain, f) correlation between the intensity of wrist pain in relation to the intensity of shoulder joint pain, g) correlation between the intensity of shoulder joint pain in relation to the intensity of lumbar spine pain, h) correlation between the intensity of wrist pain in relation to the intensity of lumbar spine pain. 
by $25 \%$ of the studied men. For comparison, among 1023 patients suffering from lumbar pain who were studied by Chinese researchers, as many as half of them also experienced cervical pain [24], which may in turn cause pain in the shoulder joints.

The existing correlation between the intensity of lumbar and cervical pain and pain in the shoulder joints may be indicative of progressive overload changes in the musculoskeletal system. Degenerative changes in the cervical spine may cause pain in the upper extremity joints. Radiculopathy, i.e., compression of nerve roots located in the cervical spine, may result in pain, tingling or numbness at various levels of the upper extremities. The nerves originating in the cervical spine form the shoulder plexus and then innervate the entire upper extremity. Degenerative changes of this part of the spine are related to the presence of hernia of the nucleus pulposus or osteophytes, which occlude the intervertebral foramina and cause the compression of nerve roots. The location and intensity of pain depend on the degree of nerve root damage; progressive pathological changes may lead to the loss of the gripping function of the hand and sensory disturbances [25-27]. Asserting that the studied men perform many non-physiological and repetitive movements prompts us to analyse the existing correlation from the other side as well. Repetitive activities and working with an additionally loaded upper extremity is conducive to the occurrence of pathological changes in the shoulder joints. Frequently occurring shoulder constriction and the accompanying pain lead to changes in the mechanics of the spine and an unfavourable body posture assumed while working. The known mechanism of transferring load may result in degenerative changes in the cervical spine joints as a result of primary ailments located in the shoulder joint [28].

In the future, the occurrence of correlations between cervical spine pain and shoulder joint pain (and others referred to in the paper) could be used to predict subsequent locations of pain in a particular workplace. However, despite the same tasks and conditions in a particular workplace, body position also constitutes a factor in predicting the occurrence of pain. This is an individual factor that depends on the knowledge of ergonomic principles and the basics of biomechanics that translate into the correct body position for a given activity.

Changes in the intensity of pain depending on age were also observed. The youngest group (20-34 y.o.) reported the lowest pain intensity. The strongest pain was experienced by men aged 35-49, which may be indicative of progressive pathological changes occurring in the spine. The strength of lumbar pain is related to changes occurring in the intervertebral discs. Degeneration, dehydration and fibrosis of the intervertebral discs occur with age [27]. However, this process takes place significantly faster if the spine is improperly or excessively loaded. Performing repetitive movements, carrying objects in an improper way or assuming an unfavourable body posture while working lead to the accumulation of loads on the small surface of the intervertebral discs [2]. Shear forces have the most negative impact because they lead to protrusion, damage of the anulus fibrosus and incorrect transfer of load by the nucleus pulposus. Fibrosis is the last stage of the degenerative disease of the intervertebral discs, which often results in a reduction of pain and is frequently accompanied by vertebral canal stenosis or reduced mobility [25]. Reduced pain in the case of individuals over the age of 50 may be therefore indicative of the occurrence of degenerative changes resulting from chronic overload disease. The concurrent increase in the frequency and intensity of pain reported by the workers (VAS scale) is also indicative of chronic pathological changes.

The lack of a relationship between the intensity of pain and the number of repetitive wrist movements performed by the workers is probably due to the workers' incorrect estimates. The number of repeated wrist movements they reported was lower and usually constituted the number of components processed during one working day. They were not aware that cleaning a single opening with the use of a compressor, for example, requires several dozen circular movements of the wrist. Assuming that one component contains several openings and a worker processes several hundred components during one working day, the number should be one order of magnitude higher than that reported by the workers. Analysis of the video and photographic materials clearly shows that physical workers are in the risk group for overload disease due to the continuous performance of repetitive movements.

Pain statistics may vary from generation to generation. Today some production lines in the automotive industry are fully automated, which completely changes the nature of the operator's work [29]. However, in automotive factories, requirements in terms of precision in particular workplaces mean that the workers employed here perform all tasks manually. In this case, one of the main objectives is to minimize the pain experienced by the workers while maintaining high productivity of the production lines. Therefore, supporting operators with an exoskeleton is a potential solution for improving the ergonomics of workplaces that require repeated movements and handling heavy objects at work while respecting industrial constraints. In various industries, manual workers experience musculoskeletal disorders (MSDs). The use of robotic devices, such as exoskeletons, may therefore be an appropriate solution for reducing the pain experienced by workers and prevent MSDs [30].

\section{Conclusions}

Results of the survey and their further analysis confirmed that in men employed in the automotive 
industry there is a statistically significant relationship between lumbar spine pain on the one hand and cervical pain in subsequent joints of the upper extremity on the other hand. The correlation between the incidence of pain in specific parts of the body can also be found in groups of workers in other industries [11-12]. The incidence of pain correlation in the automotive industry confirms the presence of workers in the MSD risk group, especially as they are exposed to a number of risk factors for musculoskeletal disorders. It is necessary to conduct specific biochemical research in order to plan therapy and, most importantly, prophylactic measures preventing the occurrence of overload disease.

\section{Conflict of Interest}

The authors declare no conflict of interest.

\section{References}

1. EU-OSHA OSH in figures [Internet]: Work-related musculoskeletal disorders in the EU - Facts and figures. Luxembourg 2010 [Cited: 12.12.2018]. Adress: https://osha. europa.eu.

2. CHIASSON M., IMBEAU D., MAJOR J., AUBRY K., DELISLE A. Influence of musculoskeletal pain on workers' ergonomic risk-factor assessments. Appl Ergon. 49, 1, 2015. https://doi.org/10.1016/j.apergo.2014.12.011.

3. PEPPOLONI L., FILIPPESCHI A., RUFFALDI E., AVIZZANO C.A. A novel wearable system for the online assessment of risk for biomechanical load in repetitive efforts. Int J Ind Ergon. 52, 1, 2015. https://doi. org/10.1016/j.ergon.2015.07.002.

4. PUNNET L. Musculoskeletal disorders and occupational exposures: How should we judge the evidence concerning the causal association? Scand J Public Health. 42 (13), 49, 2014. https://doi.org/10.1177\%2F1403494813517324.

5. PARIDAA R., RAYB P.K. Biomechanical modelling and evaluation of construction jobs for performance improvement. Work. 41 (1), 5959, 2012.

6. KARPIESIUK Ł. Automotive Industry Report. Warsaw: Polski Związek Przemysłu Motoryzacyjnego, Poland, 2015.

7. STEVENSON J.M. Looking forward by looking back: Helping to reduce work-related musculoskeletal disorders. Work. 47 (1), 137, 2014. https://doi.org/10.3233/WOR131691.

8. MACDONALD W., OAKMAN J. Requirements for more effective prevention of work-related musculoskeletal disorders. BMC Musculoskeletal Dis. 16, 293, 2013. https://doi.org/10.1186/s12891-015-0750-8.

9. Department of Economic and Social Affairs Population Division. World Population Ageing 2015. New York, 2015. No. ST/ESA/SER.A/390.

10. MATTHIAS J., JORDAN C., THEILMEIER A., WORTMANN N., KUHN S., NIENHAUS A., LUTTMANN A. Lumbar-Load Analysis of Manual Patient-Handling Activities for Biomechanical Overload Prevention Among Healthcare Workers. Ann Occup Hyg. 57 (4), 528, 2012. https://doi.org/10.1093/annhyg/mes088.
11. GAŁUSZKA R., GAŁUSZKA G., MIZIAŁEK S. Overload the musculoskeletal system in farmers-growers as a factor affecting the welfare of the. Zdrowie $\mathrm{i}$ dobrostan. 1, 113, 2015.

12. LINDEGÅRD A., WAHLSTRÖM J., HAGBERG M., VILHELMSSON R., TOOMINGAS A., TORNQVIST E.W. Perceived exertion, comfort and working technique in professional computer users and associations with the incidence of neck and upper extremity symptoms. BMC Musculoskeletal Dis. 13 (38), 2012. https://doi. org/10.1186/1471-2474-13-38.

13. CADAR I.D., POP L.V. Correlations between cervical spine posture and low back pain. HVM Bioflux, 7 (3), 179, 2015.

14. ZHANG Y., GOMES, A.T., BEER M., NEUMANN I., NACKENHORST U., KIM C.W. Reliability analysis with consideration of asymmetrically dependent variables: discussion and application to geotechnical examples. Reliab Eng Syst Safe. 185, 261, 2019.

15. ZHANG Y., KIM C.W., BEER M., DAI H., DAI S., CARLOS G. Modeling multivariate ocean data using asymmetric copulas. Coast Eng. 135, 91, 2018.

16. ZHANG Y. Investigating dependencies among oil price and tanker market variables by copula-based multivariate models. Energy. 161, 435, 2018.

17. HE L., LU Z., LI X. Failure-mode importance measures in structural system with multiple failure modes and its estimation using copula. Reliab Eng Syst Saf. 174, 53, 2018.

18. FAN Y., PATTON A.J. Copulas in econometrics. Annu Rev Econ. 6 (1), 179, 2014.

19. PAWLOSKA Z., POPIELAWSKA A. Work-related musculoskeletal disorders - Facts and figures - Poland. Luxembourg : European Agency for Safety and Health at Work, 2010. https://doi.org/10.2802/10952.

20. NEUPANE S., MIRANDA H., VIRTANEN P., SIUKOLA A., NYGÅRD C.H. Do physical or psychosocial factors at work predict multi-site musculoskeletal pain? A 4-year follow-up study in an industrial population. Int Arch Occup Enviromn Health. 86 (5), 581, 2013. https://doi. org/10.1007/s00420-012-0792-2.

21. STIEGLITZ D.D., VINSON D.R., HAMPTON M.C. Equipment-based Pilates reduces work-related chronic low back pain and disability: A pilot study. J Bodyw Mov Ther. 20 (1), 74, 2016. https://doi.org/10.1016/j.jbmt.2015.06.006.

22. KRÜGER P.E., BILLSON J.H., WOOD P.S., DO TOIT P.J. The effect of chronic low back pain on daily living and fear-avoidance beliefs in working adults. AJPHERD. 21 (1:2), 300, 2015.

23. KHAN N.S., WARKHEDKAR M.R., SHYAM K.A. Analysis of Hounsfield Unit of Human Bones for Strength Evaluation. Procedia Mater Sci. 6, 512, 2014. https://doi. org/10.1016/j.mspro.2014.07.065.

24. SHENG-YUN L., LETU S., JIAN C., MAMUTI M., JUNHUI L., ZHI S., CHONG-YAN W., SHUNWU F., ZHAO F. Comparison of Modic Changes in the Lumbar and Cervical Spine, in 3167 Patients with and without Spinal Pain. PLoS One. 9 (12), 2014. https://doi.org/10.1371/ journal.pone.0114993.

25. DZIAK A. Spine pains and dysfunctions. Medicina Sportiva, Krakow, 2007.

26. BOBER T., ZAWADZKI J. Biomechanics of the human musculoskeletal system. BK, Wroclaw, 2001.

27. KRAEMER J. Intervertebral disc diseases: Causes, diagnosis, treatment, and prophylaxis. Elsevier Urban \& Partner, Wroclaw, 2013. 
28. IQBAL Z., ALGHADIR A. Frequency of work-related musculoskeletal disorders among physiotherapists. Medycyna Pracy. 66 (4), 459, $2015 . \quad$ https://doi. org $/ 10.13075 / \mathrm{mp} .5893 .00142$.

29. LABBUS I., SCHMIDT C., DÉR A., HERRMANN C., THIEDE S. Automated production data integration for energy-oriented process chain design. Procedia CIRP. 72 (1), 551, 2018.

30. SYLLA N., BONNET V., COLLEDANI F., FRAISSE P. Ergonomic contribution of ABLE exoskeleton in automotive industry. Int J Ind Ergonom. 44 (4), 475, 2014. 